\title{
Photoinduced electron transfer in some photosensitive molecules-incorporated semiconductor/zeolites: New photocatalytic systems
}

\author{
MINJOONG YOON* and DEVENDRA P S NEGI \\ Department of Chemistry, Chungnam National University, Taejon 305 764, \\ Korea \\ e-mail: mjyoon@cnu.ac.kr
}

\begin{abstract}
An intramolecular charge transfer (ICT) molecule, $p$-N,N-dimethylaminobenzoic acid (DMABA) has been studied in zeolite and colloidal media. The ratio of ICT to normal emission (ICT/LE) is greatly enhanced in zeolites compared to that in polar solvents. The ICT emission of DMABA was quenched by increasing the concentration of $\mathrm{TiO}_{2}$ colloids, while the normal emission was slightly enhanced. Upon illumination of the heteropoly acid (HPA) incorporated $\mathrm{TiO}_{2}$ colloids, interfacial electron transfer takes place from the conduction band of $\mathrm{TiO}_{2}$ to the incorporated HPA which is also excited to catalyze the photoreduction of Methyl Orange. It is found that the interfacial electron transfer mechanism of $\mathrm{HPA} / \mathrm{TiO}_{2}$ is quite analogous to the $\mathrm{Z}$-scheme mechanism for plant photosynthetic systems. In DMABA-adsorbed $\mathrm{TiO}_{2} /$ Y-zeolite the ICT/LE ratio of DMABA is quite small implying that electron transfer takes place from DMABA to the conduction band of $\mathrm{TiO}_{2}$. This results in drastic enhancement in the photocatalytic activity of DMABAadsorbed $\mathrm{TiO}_{2} / \mathrm{Y}$-zeolite compared to free $\mathrm{TiO}_{2} / \mathrm{Y}$-zeolite.
\end{abstract}

Keywords. Semiconductor; photocatalytic; photosensitive molecule; intramolecular charge transfer; $\mathrm{TiO}_{2} / \mathrm{Y}$-zeolite.

\section{Introduction}

The consumption of energy has grown exponentially over the last two decades due to rapid industrialization and better living standards throughout the world. Among the various forms of energy available on the earth, solar energy has the greatest potential because it is available in adequate quantity in almost all parts of the world. In nature, solar energy is utilized efficiently by plants through the process of photosynthesis. Many research groups have tried to mimic this natural process in their laboratories during the past decades. One of the approaches in this direction is by employing semiconductors as the light-harvesting unit. Semiconductors under band-gap excitation produce electronhole $\left(e^{-}-h^{+}\right)$pairs, which initiate the oxidation and reduction processes of the adsorbed substrates. Several metal oxides ${ }^{1-5}$ and chalcogenides ${ }^{6-10}$ have been investigated for their photophysical and photocatalytic properties till date. They have been used to study the redox reactions of substrates like biological molecules, ${ }^{11,12}$ dyes, ${ }^{13,14}$ alcohols ${ }^{15,16}$ etc. Colloidal semiconductors have also been employed for the decomposition of toxic substances present in waste-water. The photocatalytic degradation of 4-chlorophenol, ${ }^{17}$

*For correspondence 
2-chlorophenol, ${ }^{18}$ 1,10-dichlorodecane, ${ }^{19}$ carbaryl $^{20}$ and insecticides ${ }^{21}$ have been reported recently.

Zeolites are crystalline Al-O-Si materials containing pores of molecular dimensions, interconnected by smaller windows. By using zeolites as hosts it is possible to synthesise well-defined clusters inside these pores. They have recently been used for the preparation of semiconductors like $\mathrm{CdS}^{22,23}$ and $\mathrm{TiO}_{2}{ }^{24}$ Zeolites possess unique properties like rigidity and polarity and therefore attract further studies for the clear understanding of the behaviour of the semiconductor particles in their cavities. There have been several reports on the photocatalytic activity of semiconductors entrapped in zeolite cages. ${ }^{25-28}$ Photosensitive molecules like $p$-N,N-dimethylaminobenzoic acid (DMABA) have attracted considerable attention due to the formation of an intramolecular charge transfer (ICT) state which is characterised by a phenomenon of dual fluorescence. In the present paper the photoinduced intramolecular charge transfer of DMABA in zeolite and colloidal media has been discussed. The enhanced photocatalytic efficiency upon additional incorporation of photosensitve molecules in semiconductor based colloidal and zeolite systems has also been described.

\section{Experimental}

\subsection{Preparation and spectroscopic characterisation of colloidal samples}

Colloidal $\mathrm{TiO}_{2}$ was prepared by the method described by Grätzel et al ${ }^{29}$ One gram of titanium (IV) tetraisopropoxide was dissolved in $20 \mathrm{ml}$ of 2-propanol. A $10 \mathrm{ml}$ sample of this solution was slowly dropped into $100 \mathrm{ml}$ of acidified water $(p \mathrm{H} \mathrm{1.5)}$. This mixture was stirred until it was virtually clear. After vacuum evaporation of the solvent, a transparent solution of colloidal $\mathrm{TiO}_{2}$ particles was obtained.

The absorption spectra were measured on a Cary 3E UV-Vis spectrophotometer. A high-pressure $\mathrm{Hg}$ arc lamp in conjunction with a monochromator or $450 \mathrm{~W}$ Xe lamp with cutoff filters $(\lambda \geq 320 \mathrm{~nm})$ were used as the light source. The steady-state fluorescence spectra were recorded on a scanning SLM AMINCO 4800 spectrofluorometer. Fluorescence lifetimes were measured by a time-correlated single photon counting (TCSPC) method, employing a dual-jet ps dye laser (Coherent; Model 702) synchronously pumped by a mode-locked Ar-ion laser (Coherent; Innova 200). Transient absorption measurements and laser flash photolysis experiments were carried out using a Q-switched nanosecond Nd:YAG laser $(10 \mathrm{~Hz}$, pulse width $7 \mathrm{~ns})$ with $355 \mathrm{~nm}$ excitation light and a $250 \mathrm{~W}$ tungsten lamp as the monitoring light source. The monitoring light was oriented perpendicularly to the exciting laser beam, passed through a grating monochromator and detected with a photomultiplier (Hamamatsu R-928) and a storage oscilloscope (LeCroy 9310A, $400 \mathrm{MHz}$ ). The laser flash photolysis with DMABA samples was performed using a dye laser (Spectron) synchronously pumped by a Q-switched nanosecond Nd:YAG laser.

\subsection{Preparation and characterisation of zeolite samples}

The titanium-exchanged zeolite was prepared by a method of ion exchange of HY zeolite with an aqueous solution of ammonium titanyl oxalate monohydrate, $\left(\mathrm{NH}_{4}\right)_{2} \mathrm{TiO}$ $\left(\mathrm{C}_{2} \mathrm{O}_{4}\right)_{2} \cdot \mathrm{H}_{2} \mathrm{O}$ (from Aldrich). The $\mathrm{HY}$ zeolite was synthesized by ion exchanging $\mathrm{NaY}$ zeolite $\left(\mathrm{Si} / \mathrm{Al}=2 \cdot 47\right.$, from Aldrich) with $0 \cdot 1 \mathrm{M} \mathrm{NH}{ }_{4} \mathrm{Cl}$. After rinsing the zeolite with 
triply distilled water several times, calcination was carried out at $500^{\circ} \mathrm{C}$ for $15 \mathrm{~h}$. The temperature of the sample was elevated with a rate of $3 \cdot 3 \mathrm{C} / \mathrm{min}$. The amount of the exchanged titanium cation in the zeolite was calculated by taking the amount of $\mathrm{TiO}_{2}$ left in the supernatant liquid. The ion-exchanged zeolite had 7.2 Ti species per unit cell. The $\mathrm{TiO}_{2} / \mathrm{Y}$-zeolite was characterised by $\mathrm{X}$-ray diffraction and IR spectroscopic measurements (figure 1). $\mathrm{TiO}_{2} / \mathrm{Y}$-zeolite was transferred to a Pyrex cell and activated at $200^{\circ} \mathrm{C}$ for $2 \mathrm{~h}$ under vacuum $\left(10^{-5}\right.$ Torr). Then it was shaken with a certain volume of solvent containing the photosensitive molecule for $12-15 \mathrm{~h}$. To remove the solvent the solid was dried under vacuum for $18 \mathrm{~h}$. The dried solid was transferred to quartz cell under vacuum for the spectroscopic measurements. The photosensitive molecule adsorbed- $\mathrm{TiO}_{2} / \mathrm{Y}$ zeolite was directly mixed with the aqueous solution of the probe molecule (Methyl Orange) under argon gas flow. The samples were irradiated in a merry-go-round equipped with Xe-arc lamp. After a certain period of irradiation, the sample was filtered with $0 \cdot 2 \mu \mathrm{m}$ PVDF filter to remove the zeolite and its absorption spectra measured.
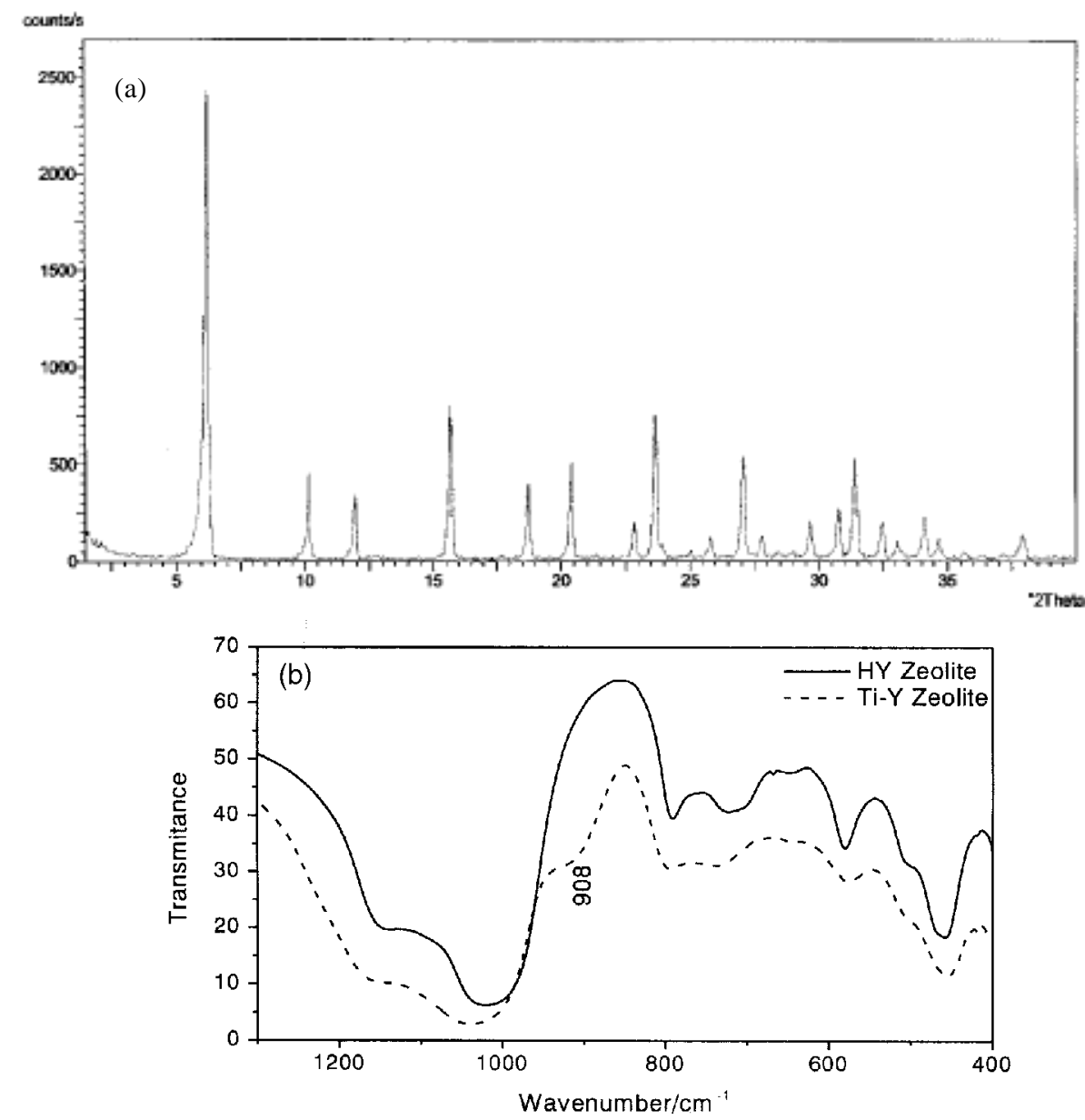

Figure 1. (a) The $\mathrm{X}$-ray diffraction pattern of $\mathrm{TiO}_{2} / \mathrm{Y}$-zeolite, and (b) the IR spectra of $\mathrm{HY}$ and $\mathrm{TiO}_{2} / \mathrm{Y}$-zeolite. 


\section{Results and discussion}

3.1 Photoinduced intramolecular charge-transfer of $p$-N,N-dimethylaminobenzoic acid in zeolite and colloidal media

In certain molecules like dimethylaminobenzonitrile derivatives, a photoinduced intramolecular charge transfer (ICT) takes place from the initially local excited state (LE) resulting in the formation of an ICT state with a large dipole moment. The formation of the excited ICT state is characterised by a phenomenon of dual fluorescence exhibiting a large Stokes' shifted emission in addition to the normal emission from the LE state. We have investigated the excited state intramolecular charge transfer properties of $p$-N,Ndimethylaminobenzoic acid (DMABA) in NaY and HY zeolite by steady-state and timeresolved fluorescence. ${ }^{30}$ The ratio of the ICT/LE emission is greatly enhanced in zeolites compared to that in homogeneous polar solvent (acetonitrile) as shown in figure 2. The time resolved fluorescence experiments showed that the decay times of ICT emission are increased from 1.4 to $2.1 \mathrm{~ns}$ with a rise time of about $20 \mathrm{ps}$. This is in accordance with the steady-state fluorescence results. The ICT/LE emission is reduced upon illumination of DMABA in NaY zeolites, which is attributed to the efficient electron transfer from the excited state of DMABA to the NaY zeolite through hydrogen bonding interaction.

The photoinduced intramolecular charge transfer in DMABA was also investigated in the presence of colloidal $\mathrm{TiO}_{2}{ }^{31}$ The ICT emission of DMABA was quenched by increasing the $\mathrm{TiO}_{2}$ concentration, while the normal emission was slightly enhanced. The fluorescence lifetimes and relative amplitudes of the ICT emission of DMABA are little affected by the addition of colloidal $\mathrm{TiO}_{2}$, while those of normal emission are greatly changed. An examination of the position of energy levels of LE and ICT states of

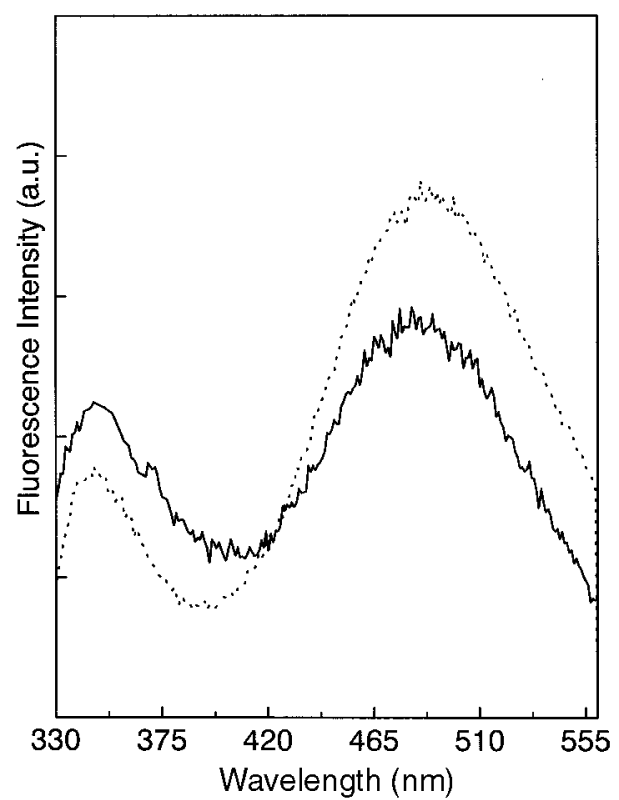

Figure 2. Fluorescence emission spectra of DMABA in acetonitrile (---) and NaY zeolite (........). The excitation wavelength is $310 \mathrm{~nm}$. 
DMABA and conduction band of $\mathrm{TiO}_{2}$ reveals that the ICT state of DMABA is energetically lower than the conduction band edge of $\mathrm{TiO}_{2}$ whereas the LE state is energetically higher than it. This indicates that the quenching of ICT emission by $\mathrm{TiO}_{2}$ is not due to electron transfer and the quenching is static in nature. Thus the participation of the ICT state of DMABA in the electron transfer can be ruled out. In order to further elucidate the electron transfer process between DMABA and $\mathrm{TiO}_{2}$, ns time-resolved transient absorption spectra of DMABA were measured at various concentrations of $\mathrm{TiO}_{2}$ in acetonitrile. For this purpose a dye laser pumped by a Q-switched ns Nd-YAG (10 Hz, pulse width $7 \mathrm{~ns}$ ) was used as the excitation source. The output of the dye laser was frequency doubled to give a laser pulse of $300 \mathrm{~nm}$. These spectra displayed two different peaks at 435 and $500 \mathrm{~nm}$. The peak at $435 \mathrm{~nm}$ was attributed to the triplet state of DMABA, while the $500 \mathrm{~nm}$ peak originated from the cation radical of DMABA. The lifetime of the triplet state of DMABA was little affected by the presence of $\mathrm{TiO}_{2}$ colloids as can be seen in figure 3 indicating that the possibility of the participation of the triplet state in the electron transfer process can be ruled out. These results support the conclusion that the
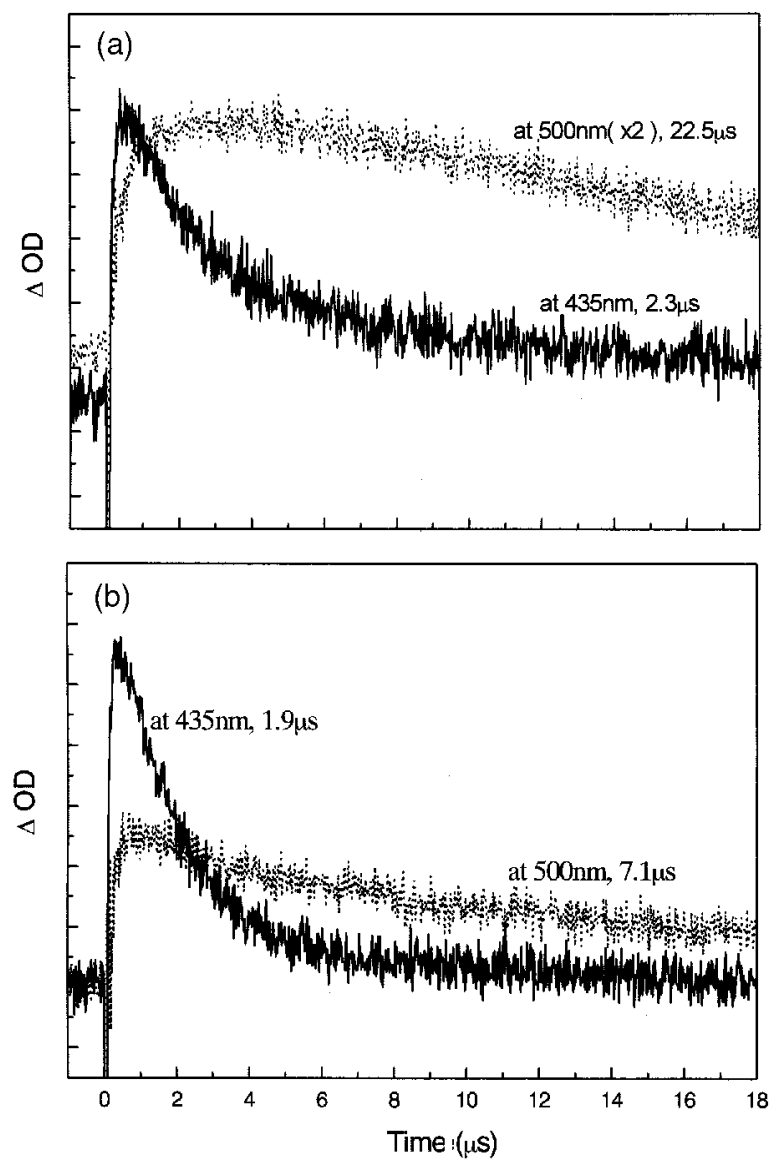

Figure 3. (a) The decay profiles of $0 \cdot 1 \mathrm{mM}$ DMABA in acetonitrile, and (b) in acetonitrile containing $4 \times 10^{-5} \mathrm{M} \mathrm{TiO}_{2}$ colloids. $\left(\lambda_{\mathrm{ex}}=300 \mathrm{~nm}\right.$. $)$ 
electron transfer into the $\mathrm{TiO}_{2}$ colloids takes place from the singlet excited state of adsorbed DMABA.

\subsection{Heteropoly acid-incorporated $\mathrm{TiO}_{2}$ photocatalytic system}

Various research groups have tried to increase the photocatalytic activity of the colloidal semiconductor system by using coupled semiconductors, ${ }^{32}$ doping with different transition metal ions ${ }^{33}$ etc. Recently Grätzel et $a l^{34}$ have developed the dye-sensitized mesoporous $\mathrm{TiO}_{2}$ solar cells with the highest photon-to-electron conversion quantum yield (33\%). We attempted to incorporate photoreactive heteropoly acid (HPA) such as $\mathrm{H}_{3} \mathrm{PW}_{12} \mathrm{O}_{40}$ into $\mathrm{TiO}_{2}$ colloids in aqueous polyvinyl alcohol (PVA), $0 \cdot 1 \%$ solution. ${ }^{35}$ Upon illumination of the $\mathrm{HPA} / \mathrm{TiO}_{2}$ system with near UV light $(300-375 \mathrm{~nm})$, the interfacial electron transfer takes place from the conduction band of $\mathrm{TiO}_{2}$ to the incorporated HPA. The nanosecond laser flash photolysis of deaerated $\mathrm{TiO}_{2}$ solution in the presence of PVA showed a transient trapped conduction electron $(120 \mu \mathrm{s})$ at $600 \mathrm{~nm}$ as observed by Bahnemann et al, ${ }^{1}$ while in the presence of HPA it is quenched by generating a longer lived transient with maximum absorption around $450 \mathrm{~nm}$ ( 40 ms) instead of the trapped electron (figure 4). The extent of the photoreduction of the HPA adsorbed on $\mathrm{TiO}_{2}$ particles depends on the concentration ratio of the HPA and $\mathrm{TiO}_{2}$ colloids, irradiation wavelength and intensity of radiation. The enhancement results can be best explained if one were to assume that the electron transfer proceeds via two photochemical reactions as the 'Z-scheme' mechanism for the plant photosynthetic system shown in (a) of scheme 1 . In scheme 1, (b) shows how the electron transfer in $\mathrm{HPA} / \mathrm{TiO}_{2}$ system proceeds via two photochemical reactions pathway. The near-UV
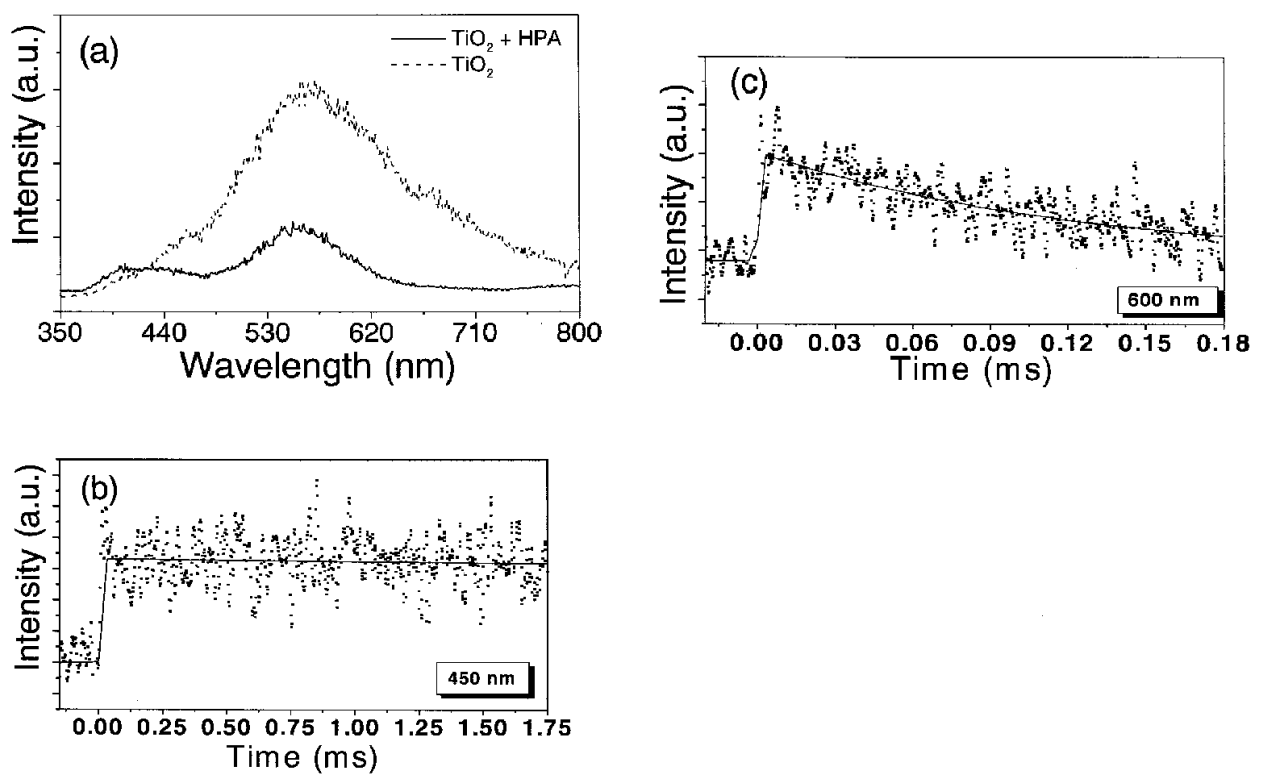

Figure 4. (a) Transient absorption spectra of $5 \times 10^{-3} \mathrm{M} \mathrm{HPA}$ with colloidal $\mathrm{TiO}_{2}$ $(5 \mathrm{~g} / \mathrm{l})$ in $0.1 \%$ PVA aqueous solution; time profiles of the absorption at 450 (b) and $600 \mathrm{~nm}(\mathbf{c})$. 


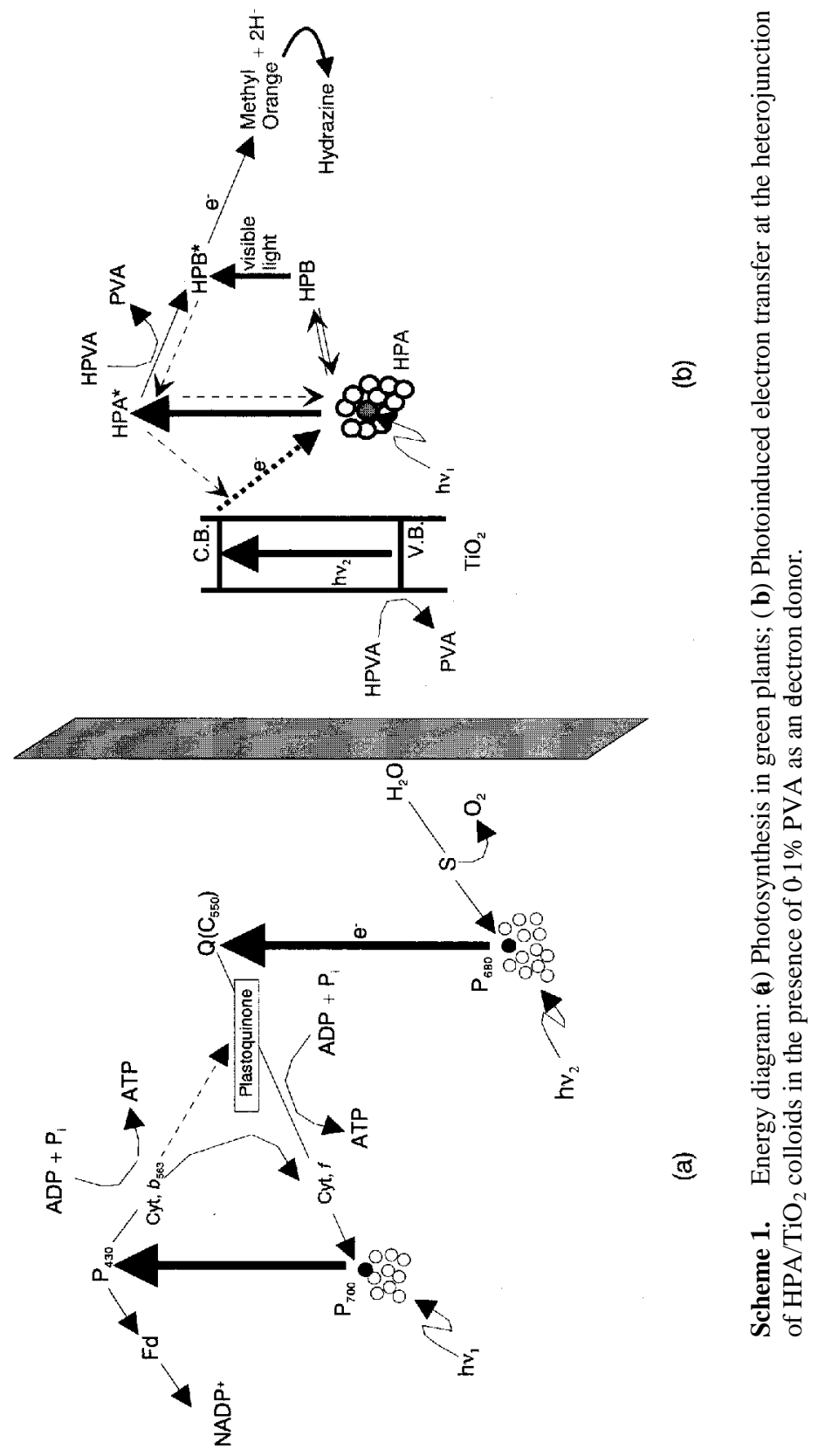


illumination of $\mathrm{HPA} / \mathrm{TiO}_{2}$ in the presence of PVA results in the charge separation in $\mathrm{TiO}_{2}$ as well as the excitation of HPA. Thus the formation of heteropoly blue (HPB) occurs by direct electron transfer from the $\mathrm{TiO}_{2}$ conduction band to the ground state of HPA as well as by photoreduction through the excited state of HPA. The catalytic activity of the HPA/ $\mathrm{TiO}_{2}$ colloids was assessed by carrying out the photoreduction of Methyl Orange in aqueous medium. When anaerobic aqueous solutions of Methyl Orange $\left(5 \times 10^{-5} \mathrm{M}\right)$ in the presence of naked $\mathrm{HPA}, \mathrm{TiO}_{2}$ or $\mathrm{HPA} / \mathrm{TiO}_{2}$ colloids were illuminated with near-UV radiation (cutoff $\geq 320 \mathrm{~nm}$ ), the visible absorption band of Methyl Orange at $502 \mathrm{~nm}$ started to disappear without a wavelength shift while no bleaching was observed in the absence of the colloid or HPA. Figure 5 shows the comparison of the photoreduction rate of Methyl Orange in the three cases. From this data, the catalytic activity of $\mathrm{HPA} / \mathrm{TiO}_{2}$ colloids (100\% bleaching within $20 \mathrm{~min})$ is tremendously increased as compared to that of naked $\mathrm{TiO}_{2}$ or HPA itself (only $60 \%$ bleaching within $60 \mathrm{~min}$ ). On the basis of the above results and using the following expression for quantum efficiency $(\phi)$

$$
\phi=\text { no. of photoreduced methyl orange molecules/no. of absorbed photons, }
$$

the photon-to-electron conversion yield in the presence of $\mathrm{HPA} / \mathrm{TiO}_{2}$ was almost $34 \%$ with $320 \mathrm{~nm}$ monochromatic light. This yield is higher than that reported by Grätzel et $a l^{34}$. Furthermore, it was found that upon additional illumination with visible light (400$600 \mathrm{~nm}$ ), the photocatalytic reduction of methyl orange was much faster as compared to the results obtained by near-UV light only $(320-390 \mathrm{~nm})$. This is consistent with the two photochemical pathways shown in scheme 1 .

\subsection{Photosensitive molecule incorporated $\mathrm{TiO}_{2} / \mathrm{Y}$-zeolite photocatalytic system}

We incorporated an ICT molecule $p$-N,N-dimethylaminobenzoic acid (DMABA) in the $\mathrm{TiO}_{2} /$ Y-zeolite framework. ${ }^{36}$ The fluorescence spectrum of DMABA in $\mathrm{TiO}_{2} / \mathrm{Y}$-zeolite exhibited dual emission bands. However the ratio of ICT emission to the local emission (ICT/LE) was quite small as compared to that of DMABA in polar zeolite cavity ${ }^{30}$ or $\mathrm{SiO}_{2}$ colloidal solution. ${ }^{37}$ This implies that there is a certain photochemical interaction between DMABA and $\mathrm{TiO}_{2} / \mathrm{Y}$-zeolite. The photochemical interaction should be an electron transfer from DMABA to the conduction band of $\mathrm{TiO}_{2}$ attached inside the nano-

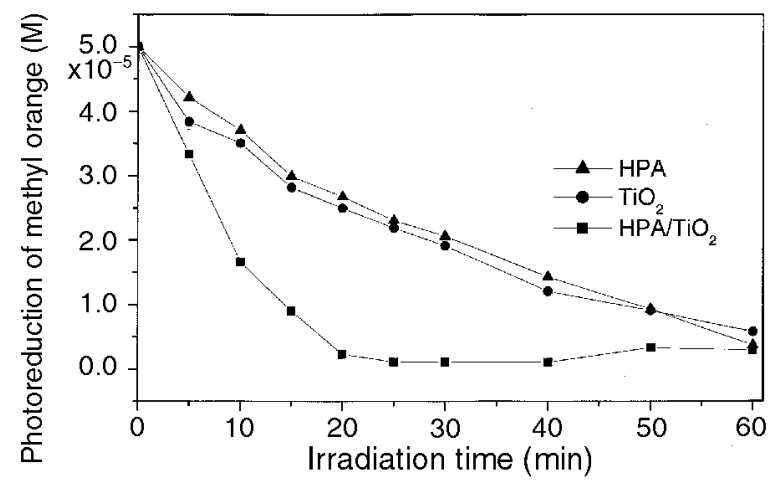

Figure 5. Photoreduction of Methyl Orange in the presence of $\mathrm{HPA}$, naked $\mathrm{TiO}_{2}$, or $\mathrm{HPA} / \mathrm{TiO}_{2}$ in $0 \cdot 1 \%$ PVA aqueous solutions as a function of irradiation time by Xe lamp $(\lambda \geq 320 \mathrm{~nm}) .\left[\mathrm{TiO}_{2}\right]=5 \times 10^{-3} \mathrm{M},[\mathrm{HPA}]=5 \times 10^{-5} \mathrm{M}$. 


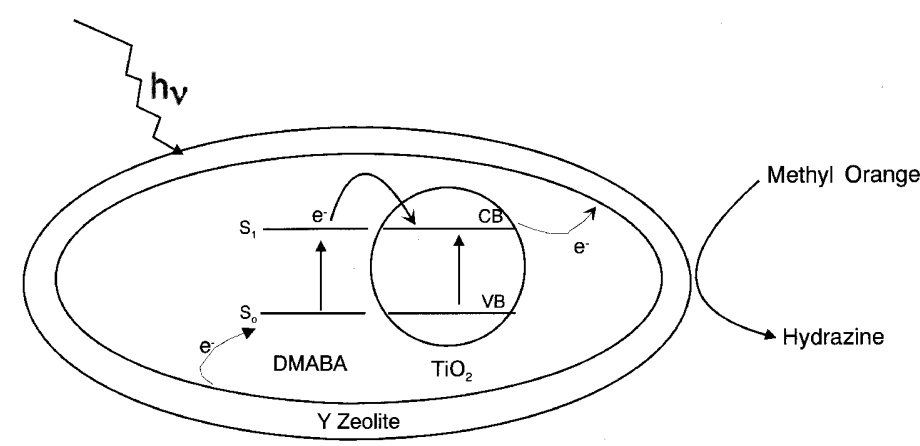

Scheme 2. Schematic diagram showing the reduction of Methyl Orange by DMABA adsorbed $\mathrm{TiO}_{2} / \mathrm{Y}$-zeolite.

pore frame of the zeolite. The photoinduced electron transfer from the locally excited singlet state of DMABA to the conduction band of $\mathrm{TiO}_{2}$ has been observed earlier in the DMABA-adsorbed $\mathrm{TiO}_{2}$ colloidal system. ${ }^{31}$ This could result in the enhancement of electron transfer efficiency to the frame of $\mathrm{TiO}_{2} / \mathrm{Y}$-zeolite and the electron should be subsequently accessible for the reduction of a substrate outside the zeolite framework. In order to test the above speculation the photoreduction of Methyl Orange $\left(5 \times 10^{-6} \mathrm{M}\right)$ was tried using DMABA-adsorbed $\mathrm{TiO}_{2} /$ Y-zeolite as the photocatalyst with light of $\lambda \geq$ $320 \mathrm{~nm}$. The photocatalytic activity of DMABA-adsorbed $\mathrm{TiO}_{2} / \mathrm{Y}$-zeolite was found to be six times higher than that of free $\mathrm{TiO}_{2} / \mathrm{Y}$-zeolite. The reduction of Methyl Orange is shown in scheme 2. The quantum efficiency of the photocatalytic reduction of Methyl Orange was about $34 \%$ with $320 \mathrm{~nm}$ light. This is same as that obtained with colloidal $\mathrm{HPA} / \mathrm{TiO}_{2}$ system. Similar experiments with Nile Red-adsorbed $\mathrm{TiO}_{2} /$ Y-zeolite showed the photocatalytic activity of about eight times higher than free $\mathrm{TiO}_{2} / \mathrm{Y}$-zeolite. ${ }^{38}$ This indicates that Nile Red-adsorbed $\mathrm{TiO}_{2} / \mathrm{Y}$-zeolite is even more efficient than the DMABAadsorbed $\mathrm{TiO}_{2} / \mathrm{Y}$-zeolite system.

Incorporation of heteropoly acid (HPA) in the $\mathrm{TiO}_{2} / \mathrm{Y}$-zeolite pores has been carried out in our laboratory and the photocatalytic efficiency of this new catalyst is currently under investigation. We anticipate that this photocatalytic system will be highly efficient for both water purification and recovery capability. We also plan to use MCM-41 molecular sieves as support for photocatalytic systems. These materials have hexagonal channels of size tunable between 15 to $100 \AA$ Thus they can be used to trap bulky molecules which cannot be encapsulated in zeolite cavities. The determination of the photocatalytic activity of DMABA adsorbed colloidal $\mathrm{TiO}_{2}$ is also under consideration.

\section{Conclusions}

The intensity ratio of ICT emission to normal emission of DMABA is dependent on the nature of chemical environment. In the HPA incorporated $\mathrm{TiO}_{2}$ colloidal system an interfacial electron transfer occurs from the conduction band of $\mathrm{TiO}_{2}$ to the HPA upon illumination by near-UV light. The photon-to-electron conversion efficiency of $\mathrm{HPA} / \mathrm{TiO}_{2}$ system is $34 \%$. The Nile Red-incorporated $\mathrm{TiO}_{2} / Y$-zeolite is more efficient than DMABA-adsorbed $\mathrm{TiO}_{2} / \mathrm{Y}$-zeolite. Such photocatalytic systems would be useful for the detoxification of water using the ultraviolet and visible portions of the sunlight. The 
photolysis of water to produce hydrogen by employing such systems can also help to solve our future energy problems. Further research is underway to develop more efficient photocatalytic systems.

\section{Acknowledgements}

This work has been financially supported by KOSEF through the Molecular Catalysis Centre at Seoul National University.

\section{References}

1. Bahnemann D, Henglein A, Lillie J and Spanhel L 1984 J. Phys. Chem. 88709

2. Koch U, Fojtik A, Weller H and Henglein A 1985 Chem. Phys. Lett. 122507

3. Kumar A, Henglein A and Weller H 1989 J. Phys. Chem. 932262

4. Chatterjee S, Sarkar S and Bhattacharyya S N 1993 J. Photochem. Photobiol. A72 183

5. Lume-Pereira C, Baral S, Henglein A and Janata E 1985 J. Phys. Chem. 895772

6. Henglein A 1982 Ber. Bunsenges. Phys. Chem. 86301

7. Dimitrijevic N M 1987 J. Chem. Soc., Faraday Trans. 1831193

8. Henglein A and Gutierrez M 1983 Ber. Bunsenges Phys. Chem. 87852

9. Chestnoy N, Hull R and Brus L E 1986 J. Chem. Phys. 852237

10. Rossetti R, Hull R, Gibson J M and Brus L E 1985 J. Chem. Phys. 831406

11. Kumar A and Negi D P S 2000 J. Photochem. Photobiol. A134 199

12. Kumar A and Negi D P S 2001 J. Colloid Interface Sci. 238310

13. Brown G T and Darwent J R 1984 J. Chem. Soc., Faraday Trans. 1801631

14. Kamat P V 1985 J. Chem. Soc., Faraday Trans. 181509

15. Harvey P R, Rudham R and Ward S 1983 J. Chem. Soc., Faraday Trans. 1791381

16. Green K J and Rudham R 1992 J. Chem. Soc., Faraday Trans. II 883599

17. Li X, Cubbage J W and Jenks W S 1999 J. Org. Chem. 648525

18. Rideh L, Wehrer A, Ronze D and Zoulalian A 1997 Ind. Eng. Chem. Res. 364712

19. El-Morsi T M, Budakowski W R, Abd-El-Aziz, A S and Friesen K J 2000 Environ. Sci. Technol. 341018

20. Pramauro E, Prevot A B, Vincenti M and Brizzolesi G 1997 Environ. Sci. Technol. 313126

21. Konstantinou I K, Sakellarides T M, Sakkas V A and Albanis T A 2001 Environ. Sci. Technol. 35398

22. Herron N, Wang Y, Eddy M M, Stucky G D, Cox D E, Moller K and Bein T 1989 J. Am. Chem. Soc. 111530

23. Fox M A and Pettit T L 1989 Langmuir 51056

24. Liu X, Ku K-K and Thomas J K 1992 Chem. Phys. Lett. 195163

25. Green K J and Rudham R 1993 J. Chem. Soc., Faraday Trans. II 891867

26. Liu X, Iu K-K and Thomas J K 1993 J. Chem. Soc., Faraday Trans. II 891861

27. Yamashita H, Ichihashi Y, Anpo M, Hashimoto M, Louis C and Che M 1996 J. Phys. Chem. 10016041

28. Hwang Y-J, Kim S-J, Park S, Yang J-H, Kim H and Choy J-H 2000 Bull. Korean Chem. Soc. 21187

29. Duonghong D, Ramsden J and Grätzel M 1982 J. Am. Chem. Soc. 1042977

30. Kim Y, Lee B I and Yoon M 1998 Chem. Phys. Lett. 286466

31. Choi J, Yeo K, Yoon M, Lee S J and Kim K 2000 J. Photochem. Photobiol. A132 105

32. Spanhel L, Weller H and Henglein A 1987 J. Am. Chem. Soc. 1096632

33. Choi W, Termin A and Hoffmann M R 1994 J. Phys. Chem. 9813669

34. Bach U, Lupo D, Comte P, Mpser J E, Weissörtel F, Salbeck J, Spreitzer H and Grätzel M 1998 Nature (London) 395583

35. Yoon M, Chang J A, Kim Y, Choi J R, Kim K and Lee S J 2001 J. Phys. Chem. B105 2539

36. Kim Y and Yoon M 2001 J. Mol. Catal. 168257

37. Kim Y, Cheon H W, Yoon M, Song N W and Kim D 1997 Chem. Phys. Lett. 264673

38. Lee J J, Kim Y and Yoon M 2001 J. Photosci. 827 